\title{
"MANGAN ORA MANGAN, SING PENTING KUMPUL" (MAKAN TIDAK MAKAN YANG PENTING KUMPUL) TINJAUAN FILOSOFIS “AKU DAN LIYAN" DALAM GAGASAN TOGETHERNESS PARA FILSUF BARAT
}

\author{
Evan Tandywijaya \\ STFT Widya Sasana \\ Malang, East Java, Indonesia \\ evantandywijaya@gmail.com
}

\begin{abstract}
Javanese people are known for their rich and profound wisdom in life. Like a water source that never stops flowing, Javanese people never run out of sources of wisdom. One of the policies of the Javanese community that has been around for a long time but remains actual until now is "mangan ora mangan sing penting kumpul". Today, the rapid development of technology makes people more individualistic and ignores the importance of togetherness. This is the background and purpose of this writing, namely as a reminder of the value of togetherness and see the depth of meaning contained in the philosophy of "mangan ora mangan sing penting kumpul". The writer want to see this philosophy in terms of the relationship between Eastern and Western philosophy and present it using narrative methods. Previous studies show that philosophy of "mangan ora mangan sing penting kumpul" has never been seen in relation with Eastern and Western philosophy. In this article, the weiter would like to present a different discussion, namely by looking at the correlation of philosophy "mangan ora mangan sing penting kumpul" with a review of Western philosophers' thoughts. Finally, the exploration of the meaning and depth of the philosophy of "mangan ora mangan sing penting kumpul" brings the writer to a discovery, namely "mangan ora magan sing penting kumpul" as a crossing of subjects - objects.
\end{abstract}

Keywords : Javanese people; Wisdom; Togetherness; Relationship; Crossing

\section{PENDAHULUAN}

Mangan ora mangan sing penting kumpul, artinya makan tidak makan yang penting kumpul. Filosofi Jawa ini terdengar usang dan kuno, namun maknanya teruji melintasi zaman, dahulu dan sekarang. Kebijaksanaan ini kelihatannya sederhana, namun makna yang terkandung di dalamnya sangat dalam. Kebersamaan adalah nilai tertinggi yang ditawarkan melalui kebijaksanaan ini.

Filosofi mangan ora mangan sing penting kumpul merupakan salah satu kebudayaan orang Jawa, khususnya mereka yang suka bersosialisasi atau bersilaturahmi, berkumpul, saling membantu dan gotong royong. Masyarakat Jawa, yang notabene belum "terkontaminasi" teknologi dan arus kebudayaan modern lebih senang berkumpul bersama keluarga dan masyarakat di sekitarnya daripada sibuk menghabiskan waktu untuk dirinya sendiri.

\footnotetext{
1 Bdk. Fatimah Ihsan, "Solidaritas Sosial Masyarakat Jawa Perantau di Kampung Jawa Kota Tanjungpinang," Jurnal Solidaritas Sosial Masyarakat Jawa Perantau di Kampung Jawa Kota Tanjungpinang (2018): 3.
} 
"Mangan ora mangan sing penting
kumpul" ingin mengatakan bahwa
masyarakat Jawa lebih mementingkan
acara bersama (berkumpul bersama keluarga) meski tidak ada makanan yang tersedia. $^{2}$ Di samping itu, filosofi Jawa kuno ini ingin menunjukkan sisi lain yang dimiliki masyarakat Jawa, yang tidak dimiliki oleh masyarakat lain. Selagi masyarakat lain mengejar pendapatan dan kekayaan untuk memuaskan hidup mereka, masyarakat Jawa lebih memilih untuk menerapkan nilai kebersamaan dan relasi interpersonal di atas segalanya. ${ }^{3}$ Hal ini membuat masyarakat Jawa bersifat lebih egaliter, demokratis, dan inklusif.

Masyarakat Jawa menyambut dengan hangat dan tangan terbuka siapa saja yang masuk ke dalam ranah kehidupan mereka. Mereka sangat menjunjung tinggi nilai persaudaraan dan keharmonisan. Oleh karena itu, masyarakat Jawa mewajibkan diri untuk menjalin hubungan yang baik dengan tetangga maupun orang di sekitar mereka. ${ }^{4}$ Hal ini dipengaruhi oleh sifat dan karakter mereka yang ramah, ringan tangan, dan terbuka. Keterbukaan semacam ini jarang ditemukan dalam kehidupan masyarakat lain. Keterbukaan yang dimiliki oleh masyarakat Jawa ini kemudian didukung dengan adanya semangat gotong royong yang mendarah-daging dalam kehidupan masyarakat Jawa. Akibatnya, terjalinlah suatu rasa kekeluargaan yang sangat erat di antara orang-orang Jawa. Kekeluargaan memang merupakan salah satu elemen

\footnotetext{
${ }^{2}$ Bdk. Nawi $\mathrm{Ng}$, et al., "Is self-rated health an independent index for mortality among older people in Indonesia?," Jurnal PloS one 7.4 (2012): 6.

3 Bdk. Yusak Irawan, "Subjective Well Being in Javanese Collectivistic Culture," dalam Proceeding International Conference of Revisited Asian Society, eds. Christina Siwi dan Monica Eviandaru (Yogyakarta: Tp, 2014): 328.

${ }^{4}$ Bdk. Moh. Roqib, Harmoni dalam Budaya Jawa, Purwokerto: STAIN Purwokerto Press, 2007, 61.
}

penting dari kehidupan masyarakat Jawa. Dengan demikian, filosofi mangan ora mangan sing penting kumpul mendapat peran penting dalam prinsip kekeluargaan yang dimiliki masyarakat Jawa. Ia menjadi keutamaan dan pedoman umum bagi masyarakat Jawa untuk berelasi dan membangun kehidupan bersama.

Filosofi "Mangan ora mangan sing penting kumpul" juga mengungkapkan suatu prinsip kebersamaan, suatu ajaran sosial masyarakat Jawa yang luhur. Sebenarnya, mangan ora mangan sing penting kumpul mengandung arti yang saling kontradiktif. Kata mangan, yang dalam bahasa Indonesia berarti "makan" merupakan suatu hal yang sangat personal. Seseorang melakukan aktivitas makan untuk keberlangsungan hidupnya sendiri. Sedangkan, kata "kumpul" bermakna sosial. Ia memiliki makna inter/intra personal di dalam dirinya. Lantas, bagaimana orang Jawa memaknai dua hal yang saling kontradiktif ini dan memakainya dalam kehidupan sehari-hari? Seperti yang telah penulis bahas di atas, bahwa masyarakat Jawa sangat menjunjung tinggi nilai kebersamaan. Mangan ora mangan sing penting kumpul dapat saja diartikan secara dangkal yakni, tanpa adanya makanan yang penting berkumpul. Namun, pengertian semacam ini tampaknya kurang tepat, melihat masyarakat Jawa yang senang berefleksi dan memaknai segala sesuatu secara mendalam.

Akhirnya, filosofi mangan ora mangan sing penting kumpul bisa dilihat sebagai "perang nilai/ keutamaan" di dalam diri manusia, yakni perang antara dimensi personal dan inter/ intra personal. Dimensi personal dalam kata mangan sangat erat kaitannya dengan kepentingan individu. Sedangkan dimensi komunal atau sosial dalam kata "kumpul" sangat erat kaitannya dengan kepentingan bersama. Singkatnya, filosofi mangan ora mangan sing penting 
kumpul ingin mengatakan kepada kita bahwa kepentingan bersama perlu menjadi prioritas dan berada di atas kepentingan pribadi. Dengan demikian, manusia dapat memaknai dirinya dengan benar sebagai makhluk sosial yang mengutamakan relasi dengan sesama di atas kepentingan pribadi.

\section{"Aku" dalam Mangan Ora Mangan Sing Penting Kumpul}

Dalam pembahasan di atas, telah penulis jelaskan bahwa kata mangan identik dengan hal yang sangat personal. Kata mangan mengarah pada relasi dengan diri sendiri. dalam bukunya yang berjudul "Relasionalitas", Prof. DR. Armada Riyanto, CM mengungkapkan sebuah gagasan mengenai "Aku" berelasi, berkomunikasi. Lebih lanjut, ia mengatakan bahwa sesungguhnya manusia memiliki kodrat komunikatif dalam kehadirannya. Jika demikian, hal ini berarti bahwa dalam kesendirian, manusia belum berelasi. $^{5}$ Manusia hanya bisa berelasi jika memiliki "Aku" di dalam dirinya.

Dalam filosofi mangan ora mangan sing penting kumpul, tersirat ke-Aku-an masyarakat Jawa, yang berarti masyarakat Jawa berelasi, berkomunikasi. Mangan berarti bahwa manusia itu sendirian. Ia tidak berelasi, tidak juga berkomunikasi. Namun, hanya dengan "kumpul", manusia memperoleh kepenuhannya. Ia menjadi makhluk komunikatif. Ia berelasi, berkomunikasi. "Kumpul" menampilkan kenyataan bahwa setiap manusia (Jawa) adalah Being yang komunikatif, ia adalah subjek dalam komunikasi. Dan, hanya dengan "kumpul", manusia (Jawa) dimungkinkan untuk berkomunikasi dan berkolaborasi satu sama lain. ${ }^{6}$ Singkat kata, dalam menghidupi filosofi mangan

5 Bdk. Armada Riyanto, Relasionalitas, Yogyakarta: Kanisius, 2018, 204.

${ }^{6}$ Bdk. Ibid., 230. ora mangan sing penting kumpul, masyarakat Jawa ditantang untuk melepas kesendiriannya dan memasuki kesadaran komunikatif yang ada di dalam diri sesamanya.

Mangan ora mangan sing penting kumpul berarti masyarakat Jawa memasuki kesadaran komunikatif, di mana ia berelasi, berkomunikasi. Di samping itu, masyarakat Jawa juga memasuki cinta relasional. ${ }^{7}$ Ia tidak lagi mengabdi pada diri sendiri, melainkan berelasi dengan kesadaran "Aku" yang lain (liyan), yang berada di luar dirinya. Ruang atau tempat antara kesadaran "Aku" dan "Liyan" untuk berelasi adalah cinta. Di dalam cinta, "Aku" dan "Liyan" melebur menjadi satu dan membentuk "kita". 8 Dengan demikian, dalam mangan ora mangan sing penting kumpul terdapat cinta relasional, yang mesra, yang mendalam, yang transendental. Orang tidak lagi mementingkan "Aku"nya, yang tercermin dalam mangan, melainkan berelasi, berkomunikasi dengan "Aku" yang lain, yang berada di luar dirinya (kumpul). Di dalam cinta, mangan ora mangan sing penting kumpul berubah menjadi kesadaran "Kita", kesadaran di mana keegoisan dan tendensi pribadi dikesampingkan untuk lebih mengutamakan kebersamaan dan persaudaraan dalam cinta relasional "Aku" dan "Liyan", cinta "Kita".

Dalam bukunya, Relasionalitas, Prof. DR. Armada Riyanto membagi transendensi cinta ke dalam lima komponen ${ }^{9}$ yang saling bersinergis, yaitu:

\footnotetext{
${ }^{7}$ Cinta relasional, seperti apa yang ditulis oleh Prof. DR. Armada Riyanto dalam bukunya Relasionalitas, ingin mengatakan bahwa ada usaha dari kesadaran "Aku" untuk mengenal secara terus-menerus kesadaran akan eksistensi "Liyan". Cinta berarti pertemuan antara Aku dan Liyan. Bdk. Ibid., 373. ${ }^{8}$ Bdk. Ibid., 374.

${ }^{9}$ Menurut Prof. DR. Armada Riyanto, transendensi cinta yang paling besar ada dalam ungkapan Kristus, yakni "Tidak ada cinta yang lebih besar daripada dia
} 
1. Cinta itu mengenal gradasi kedalaman

2. Cinta itu mengenal rujukan

3. Cinta terdiri dari perbuatan "memberi"

4. Tidak ada cinta yang melebihi tindakan memberi nyawanya

5. Cinta adalah tindakan memberi untuk sahabat

Menurut hemat penulis, kedalaman filosofi mangan ora mangan sing penting kumpul juga mendapat tempatnya dalam transendensi cinta. Pertama, Masyarakat Jawa lebih memperhatikan kebersamaan dibandingkan kepentingan pribadinya. Hal ini membuat masyarakat Jawa berada dalam cinta yang tidak tunggal, tidak konstan, dan tidak statis, cinta yang tidak hanya memikirkan dirinya sendiri melainkan juga orang lain. Kedua, Masyarakat Jawa biasa berkumpul untuk memanjatkan doa, sedangkan doa merupakan sarana untuk berkomunikasi dan berelasi dengan Sang Cinta, Tuhan. Ketiga, dengan berkumpul berarti masyarakat Jawa telah memberikan diri mereka sendiri sebagai suatu persembahan bagi sesamanya. Dengan berkumpul berarti mereka juga telah memberikan waktu dan perhatian kepada sesamanya. Keempat, meski berkumpul tidak identik dengan memberikan nyawa sebagai tindakan tertinggi transendensi cinta, namun masyarakat Jawa rela memberikan diri, waktu, dan perhatian mereka kepada sesama, yang mungkin merupakan salah satu sikap hidup yang mencerminkan pemberian diri secara total. Kelima, kebersamaan dan kekeluargaan merupakan nilai-nilai pokok yang kerap dijunjung tinggi dalam kehidupan masyarakat Jawa. Oleh karena itu, memberi untuk sahabat, yang menjadi unsur kelima dari transendensi cinta juga hidup dalam diri

yang memberikan nyawanya bagi para sahabatnya". Bdk. Ibid., 377-379. masyarakat Jawa, hidup dalam kebersamaan, kekeluargaan, dan persahabatan, hidup dalam "Kita".

Dengan demikian, filosofi mangan ora mangan sing penting kumpul menjadi hidup dan semangat masyarakat Jawa, di mana mereka berelasi bukan hanya dengan diri mereka sendiri dalam kesadaran "Aku", melainkan juga dengan orang lain dalam kesadaran "Liyan". Kebersamaan masyarakat Jawa telah menjadi bukti bahwa mereka hidup dalam relasi cinta dengan sesamanya. Cinta ini bukan sembarang cinta. Cinta dalam filosofi mangan ora mangan sing penting kumpul adalah cinta relasional, cinta yang transendental, cinta yang rela memberi ke"Aku"annya, cinta yang rela sakit demi sesamanya, cinta yang total.

\section{Simbolisme Filosofi Mangan Ora Mangan Sing Penting Kumpul dalam Kehidupan Masyarakat Jawa ${ }^{10}$}

Manusia adalah makhluk ciptaan Tuhan yang paling kompleks. Ia tinggal dan hidup di dalam suatu kebudayaan tertentu. Kebudayaan sendiri terdiri dari gagasan-gagasan, simbol-simbol, dan nilai-nilai sebagai hasil karya dan perilaku manusia. ${ }^{11}$ Kebudayaan, sedemikian kaya dan luasnya dengan demikian memerlukan simbol-simbol tertentu yang dapat mengungkapkan makna terdalamnya. Simbol dapat berupa lukisan, perkataan, tari-tarian, patung, rambu-rambu, warna, tindakan, kegiatan, tradisi, dll.

Dalam pembahasan filosofi mangan ora mangan sing penting kumpul, penulis akan melihat beberapa kegiatan yang

\footnotetext{
${ }^{10}$ Masyarakat Jawa yang penulis maksud ialah para warga RT (Rukun Tetangga) yang tinggal di sekitar Seminari Tinggi CM unit Badut (Jl. Raya Candi $\mathrm{V} / 62 \mathrm{~B})$.

11 Bdk. Budiono Herusatoto, Simbolisme dalam Budaya Jawa, Yogyakarta: PT. Hanindita Graha Widya, 1987, 10.
} 
kiranya menjadi simbol kebersamaan kebudayaan masyarakat Jawa: ${ }^{12}$

1. Paguyuban Rukun Tetangga (RT). Dalam kegiatan ini, para warga RT (khususnya bapak-bapak) berkumpul di salah satu rumah warga untuk melakukan suatu pertemuan. Mereka berkumpul setiap hari Sabtu pukul 19.00-20.30 WIB. Mereka melakukan paguyuban ini di tempat yang berbeda setiap minggunya, yakni di rumah-rumah warga secara bergiliran. Adapun beberapa acara di dalam kegiatan paguyuban ini, antara lain: cangkrukan sambil ngopi dan makan snack, doa bersama (didoakan secara Islam), dan arisan RT. Dalam kegiatan paguyuban ini, tindakan ngopi dan makan snack bukanlah tujuan utama kegiatan ini, melainkan simbol kebersamaan. Dengan makan dan minum bersama, diharapkan terjalinlah suasana keakraban dan kebersamaan (kumpul) di antara warga RT. Paguyuban akhirnya menjadi simbol kebersamaan antar warga RT, yang melukiskan relasi cinta antar warga RT.

2. Slametan. Istilah slametan ini sendiri berasal dari kata selamat yang dalam KBBI daring berarti kenduri untuk meminta selamat. ${ }^{13}$ Tradisi slametan biasanya diadakan sebagai bentuk rasa syukur atas anugerah dan kebaikan Tuhan yang diberikan kepada manusia. Masyarakat Jawa (terutama warga RT di sekitar Seminari Tinggi CM) biasanya mengadakan slametan dengan mengundang warga sekitar RT dan

\footnotetext{
${ }^{12}$ Tindakan dan kegiatan yang penulis bahas di sini secara khusus merupakan tindakan dan kegiatan yang pernah dan sedang penulis ikuti selama ini. Locus atau tempat yang penulis maksudkan adalah di daerah sekitar penulis tinggal (dalam hal ini Seminari Tinggi CM).

KBBI daring, https://kbbi.kemdikbud.go.id/entri/selamatan, diakses pada 19 Oktober 2018.
}

kerabat dekat mereka. Mereka kerap mengadakan slametan dalam rangka: kelahiran, sunatan, pernikahan, kematian, naik haji, renovasi rumah, dll. Dalam tradisi ini, tuan rumah atau RT yang menyelenggarakan slametan menyuguhkan makanan dan minuman sebagai bentuk terima kasih mereka atas kehadiran, kebersamaan, kekeluargaan, persahabatan yang terjalin dalam acara tersebut. makanan dan minuman, meski merupakan salah satu unsur penting yang ada dalam tradisi slametan, bukanlah unsur utama yang menjadi tujuan dan tonggak tradisi ini. Tujuan tradisi slametan tidak lain adalah agar masyarakat Jawa semakin guyub dan rukun, semakin memiliki rasa persaudaraan, kekeluargaan, dan rasa syukur, serta mengutamakan kebersamaan di dalam kehidupan keseharian mereka.

3. Gotong Royong RT. kegiatan gotong royong rutin dilakukan (oleh warga $\mathrm{RT}$ di sekitar Seminari CM) satu kali dalam satu bulan. Dalam kegiatan ini, bapak-bapak secara khusus mendapat bagian untuk membersihkan lingkungan di sekitar RT, sedangkan ibu-ibu bertugas untuk menyiapkan konsumsi selama kegiatan ini berlangsung. Biasanya waktu untuk gotong royong dibagi menjadi dua: Bagian pertama adalah kerja besar seperti memotong rumput, mencabut rumput, memotong dahan pohon yang menutupi jalan, menyapu jalan, memotong bambu, membersihkan selokan, dll. Sebelum bagian kedua, biasanya ibu-ibu mengeluarkan "amunisi" mereka (snack dan minuman dingin) untuk membangkitkan kembali semangat bapak-bapak yang terkuras setelah kerja pada bagian pertama tadi. Bagian kedua adalah kerja ringan yang mencakup membuang sampah anorganik, membakar dan menimbun sampah 
organik, membereskan alat-alat kerja, dll. pada kegiatan gotong royong ini, makanan dan minuman menjadi simbol penyemangat bagi para warga RT (bapak-bapak) agar berjuang terus memelihara lingkungan tempat mereka tinggal. Selain itu, makanan dan minuman yang disediakan oleh ibu-ibu RT juga menjadi simbol kebersamaan yang menyatukan kembali para warga setelah melakukan pekerjaan berat (gotong royong).

\section{Togetherness, Plurality, dan mangan ora mangan sing penting kumpul}

Istilah togetherness atau yang dalam bahasa Indonesia dapat diartikan dengan kebersamaan, berasal dari bahasa Jerman yang berarti to gather atau mengumpulkan. Hal ini menunjukkan kedekatan, persahabatan, dan usaha yang terbagi atas komponen-komponen individu, tanpa mengurangi latar belakang kesendirian dan keunikan. ${ }^{14}$ Gagasan kebersamaan ini menyimpan wawasan fenomenologi, mengakui komponen-komponen penting dari konflik dan kesendirian yang hadir dalam perjumpaan. Ia menawarkan kritik konstruktif atas gagasan-gagasan relasional yang mendalam dan mutualitas. ${ }^{15}$

Lebih lanjut, Schwyzer mengatakan ada tiga gagasan yang terkandung di dalam kebersamaan: ${ }^{16}$
1. Kebersamaan subjek dengan dirinya sendiri
2. Kebersamaan subjek dengan objeknya

\footnotetext{
14 Bdk. Manu Bazzano, "Togetherness: intersubjectivity revisited," Jurnal Person-Centered \& Experiential Psychotherapies 13.3 (2014): 209.

${ }^{15}$ Bdk. Ibid., 214.

16 Richard E. Aquila, "On Plotinus and the "Togetherness" of Consciousness," Journal of the History of Philosophy 30.1 (1992): 12.
}

3. Kebersamaan subjek dengan
bagian-bagian internal di dalam
dirinya
Melihat definisi dan komponen yang ada di dalam togetherness (kebersamaan) ini, penulis berasumsi bahwa dalam kebersamaan terdapat relasi yang kuat antara pribadi yang satu dengan pribadi yang lain. Meski demikian, relasi yang kuat tersebut tetap tidak menghilangkan kekhasan dan keunikan masing-masing pribadi yang berelasi. Sementara itu, filosofi mangan ora mangan sing penting kumpul tampaknya masuk ke dalam gagasan kebersamaan subjek dengan objeknya. Gagasan kebersamaan subjek objek ini akan dibahas dalam pembahasan selanjutnya.

Orang kerap berpendapat bahwa di dalam kebersamaan semua dapat diatasi, di dalam kebersamaan tidak ada perbedaan. Namun, faktanya adalah di dalam kebersamaan terdapat pluralitas, antara lain pluralitas ide, gagasan, karakter, sifat, dan lain sebagainya. Di dalam kebersamaan ada persoalan mengenai pluralitas yang cukup besar untuk dijawab. William James, seorang filsuf Amerika pada abad ke-19 bertanya, "How can many consciousnesses be at the same time one consciousness? How can one and the same identical fact experience itself so diversely? The struggle was vain; I found myself in an impass". 17 William James mempertanyakan bagaimana beberapa atau banyak kesadaran bisa dalam waktu yang bersamaan dapat menjadi satu kesadaran dan bagaimana satu fakta pengalaman yang sama dan identik dapat sangat beragam. Pertanyaan William James tampak jelas dalam pengalaman masyarakat Jawa dengan filosofi khasnya, mangan ora mangan sing penting kumpul. Dalam mangan ora mangan sing penting kumpul,

17 Bdk. William James, A Pluralistic Universe, 
kesadaran dari masing-masing individu menjadi satu dan membentuk kebersamaan, suatu entitas rasio yang satu sekaligus beragam di dalam dirinya.

Meski William James mengalami kebuntuan dalam hal ini, namun Paul Weiss, seorang filsuf Amerika pada awal abad ke-20, tampaknya berhasil menjawab kebuntuan tersebut. Paul Weiss mengatakan bahwa di dalam pluralitas dan kebersamaan, kesadaran aku bukan lagi berada di luar kesadaran orang lain (kamu), melainkan masuk di dalam kesadaran orang tersebut. ${ }^{18}$ Dengan kata lain, di dalam pluralitas dan kebersamaan, kesadaran aku dan kamu sudah melebur menjadi satu, yakni kesadaran kami. Demikian pula yang terjadi di dalam mangan ora mangan sing penting kumpul, meski terbentuk dari bermacam-macam kesadaran (kesadaran aku dan kesadaran kamu "majemuk") dan kaya akan pluralitas, namun sebenarnya ia merupakan sebuah kesadaran bersama, kesadaran kami. Hal ini menjawab pula pertanyaan Wiliam James mengenai bagaimana satu fakta pengalaman yang sama dan identik dapat sangat beragam. Filosofi mangan ora mangan sing penting kumpul memiliki satu pengalaman yang bersifat sama dan identik, namun ia juga memiliki keberagaman di dalam dirinya. Ia sekaligus satu dan juga banyak.

\section{Kritik atas Filosofi Mangan Ora Mangan Sing Penting Kumpul}

Tariq Modood dalam artikelnya yang berjudul "Their Liberalism and Our Multiculturalism" mengatakan demikian:

Viewing a culture in terms of options and choices is an inadequate

\footnotetext{
18 Bdk. Richard J. Bernstein, "Human Beings: Plurality and Togetherness," Jurnal The Review of Metaphysics 35.2 (1981): 354.
}

characterisation of how we are constituted by and relate to our own culture. Some people would say they love their culture and are not sufficiently detached from it to evaluate it in terms of its functions. ${ }^{19}$

Beberapa orang akan mengatakan bahwa mereka mencintai budaya mereka namun tidak cukup terlepas darinya untuk melakukan evaluasi dalam fungsi-fungsi terminologinya. Rasa cinta terhadap budaya Jawa hendaknya tidak membutakan seseorang dalam melihat filosofi mangan ora mangan sing penting kumpul secara holistik atau menyeluruh. Memang benar bahwa di dalam filosofi ini terdapat nilai kebersamaan yang sangat penting bagi kehidupan masyarakat Jawa, namun kebersamaan ini bukan tidak berdampak. Salah satu dampak yang akan sangat terasa adalah terbatasnya ruang privat bagi orang-orang yang menghidupi filosofi ini. Maksudnya ialah ketika seseorang memberikan seluruh dirinya bagi sebuah komunitas, maka hanya tersisa sedikit saja bagian dari dirinya yang merupakan ruang privat yang dapat ia nikmati sendiri. Mungkin hal ini terkesan mengada-ada, namun inilah fakta yang terjadi, bahwa orang-orang yang kerap memberikan diri secara total bagi komunitas, kerap kehilangan ruang privat yang dapat mereka nikmati sendiri. Oleh karena itu, sangat penting bagi masyarakat Jawa untuk membagi waktu dan mengalokasikan lebih banyak ruang bagi dirinya sendiri agar tersedia waktu untuk berefleksi dan mengevaluasi diri.

\section{Kebersamaan Subjek - Objek adalah Relasi Aku dan Liyan}

\footnotetext{
19 Tariq Modood, "Their liberalism and our multiculturalism?" British Journal of Politics and International Relations 3(2) 2001: 247.
} 
Gagasan kebersamaan subjek - objek yang dicanangkan oleh Schwyzer di atas bisa disandingkan dengan relasi Aku dan Liyan dalam filosofi Timur. Jika dalam kebersamaan subjek - objek, kesadaran subjek tidak lagi berada di luar kesadaran objek, melainkan di dalamnya, demikian pula halnya dengan relasi Aku dan Liyan. Relasi Aku dan Liyan mengisyaratkan suatu kebersamaan di dalam dirinya. Relasi Aku dan Liyan berarti hubungan antarpribadi yang saling memiliki "Aku". Sebuah relasi hanya dapat ada jika berhubungan dengan pribadi yang lain, pribadi yang juga memiliki "Aku". ${ }^{20}$

Lantas, di manakah letak kebersamaan dalam konteks filosofi mangan ora mangan sing penting kumpul? Letaknya di sini, yakni dalam frasa sing penting kumpul atau yang dalam bahasa Indonesia berarti "yang penting kumpul". Frasa sing penting kumpul ingin mengatakan bahwa masing-masing pribadi "Aku yang berelasi" mau mengenal pribadi "Aku yang berelasi" yang lain. Aku dan kamu tidak lagi menjadi sorotan utama dalam relasi ini, melainkan kebersamaan antar "Aku yang berelasi". Di sini terbentuklah relasi "kita", realitas hubungan personal, relasi antara pribadi-pribadi yang mencetuskan kita. $^{21}$

Jika demikian, tidak ada lagi hubungan subjek - objek dalam mangan ora mangan sing penting kumpul, yang ada hanya hubungan subjek - subjek. kesadaran subjektif pribadi "Aku" terletak pula di dalam kesadaran subjektif "Aku yang lain". Hal ini dikarenakan antarpribadi "Aku" sudah saling mengenal satu sama lain. Lantas, bagaimana jika antar pribadi Aku belum mengenal satu sama lain? Hal

\footnotetext{
${ }^{20}$ Bdk. Armada Riyanto, "Filsafat Aku," dalam Armada Riyanto, Marcellius Ari Cristy dan Paulus Punjung Widodo (eds.), Aku dan Liyan, Malang: Widya Sasana Publication, 2011, 13.

21 Bdk. Armada Riyanto, Berfilsafat Politik, Yogyakarta: Kanisius, 2011, 196.
}

ini akan dibahas pada pembahasan selanjutnya dalam mangan ora mangan sing penting kumpul, suatu penyeberangan antar subjek.

Dengan demikian, kebersamaan subjek - subjek menjadi salah satu ciri khas masyarakat Jawa yang tidak pernah lepas dari kesadaran mereka sebagai "Aku yang mencintai". Kesadaran yang demikian disebut kesadaran "Aku yang mencintai" tidak lepas dari pengertian bahwa cinta adalah sebuah perjumpaan Aku dan Liyan. ${ }^{22}$ Karena di dalam "kumpul" tidak hanya sekedar ada makan saja, melainkan ada cinta. Kesadaran masyarakat Jawa untuk berkumpul berarti kesadaran untuk mencintai sesamanya. Kebersamaan mereka menciptakan suatu ruang lingkup atau wilayah baru, yakni wilayah kedalaman cinta.

Akhirnya, Kebersamaan subjek subjek yang terjadi di antara masyarakat Jawa itu berciri menyempurnakan. Subjek yang berinteraksi atau yang berelasi dengan subjek lain di luar dirinya, menemukan kesempurnaan di dalam diri subjek yang lain. Subjek (Aku) jika belum berelasi dengan sesamanya belum dapat dikatakan penuh atau sempurna. Ia (subjek) seakan-akan memiliki "ruang kosong" di dalam dirinya untuk diisi oleh sesamanya. Hal ini disebut oleh Ortega y Gaset sebagai dia yang belum penuh. ${ }^{23}$

Gagasan mengenai manusia adalah "dia yang belum penuh" ingin menunjukkan kodrat relasional manusia. Manusia yang berelasi berarti manusia yang memberi ruang agar manusia lain memenuhi dirinya. ${ }^{24}$ Kehadiran orang lain mengisi ruang kosong di dalam dirinya dan sekaligus memberi kepenuhan baginya.

\footnotetext{
22 Bdk. Armada Riyanto, Relasionalitas, Op. Cit., 373.

${ }^{23}$ Bdk. Armada Riyanto, Aku dan Liyan, Op. Cit., 18. ${ }^{24}$ Bdk. Ibid., 19.
} 
Bagi masyarakat Jawa hal ini menjadi sangat bermakna, karena dengan menghidupi kebijaksanaan mangan ora mangan sing penting kumpul, berarti mereka berusaha mencari kepenuhan dan kesempurnaan hidup sebagai manusia. Mereka sadar bahwa mereka belum sempurna, "belum penuh", oleh karena itu mereka berusaha untuk menyempurnakan diri, menjadikan diri mereka "penuh" dengan kehadiran orang lain di dalam hidupnya. Dengan kata lain, masyarakat Jawa berusaha menuju ke kesempurnaan hidup dengan menghayati kodrat relasional mereka.

\section{Mangan Ora Mangan Sing Penting Kumpul, Suatu Penyeberangan Antar Subjek}

Menyeberang adalah suatu tindakan berpindah, bergerak dengan menggunakan suatu sarana dari satu tempat ke tempat lain. Sedangkan penyeberangan adalah suatu proses atau cara perbuatan menyeberang. ${ }^{25}$ Pertama-tama, dalam pembahasan ini penulis ingin memberikan suatu ilustrasi mengenai penyeberangan. Adalah jembatan Suramadu yang menghubungkan antara Surabaya dan Madura. Dulu, sebelum jembatan Suramadu ada, jika seseorang ingin menyeberang dari Surabaya ke Madura harus menggunakan kapal. Sekarang, ketika jembatan Suramadu sudah ada, akses ke Madura oleh orang-orang dari Surabaya atau ke Surabaya oleh orang-orang dari Madura menjadi lebih mudah. Singkatnya, jembatan Suramadu menjadi sarana penyeberangan yang efektif dan memudahkan seseorang untuk mengakses daerah yang ia tuju (Surabaya maupun Madura).

\footnotetext{
$25 \quad$ KBBI daring, https://kbbi.kemdikbud.go.id/entri/penyeberangan, diakses pada 1 November 2018.
}

Penyeberangan antar subjek dalam mangan ora mangan sing penting kumpul seperti orang yang sedang menyeberang melalui jembatan Suramadu. Ia bergerak menuju pribadi yang lain. Kesadaran "Aku" miliknya bergerak mendekati kesadaran "Aku" orang lain, dengan suatu proses atau cara yang unik dan khas. Menurut Prof. DR. Armada Riyanto, proses penyeberangan ini disebut persahabatan. Tindakan ini bukan suatu tindakan serentak, sekali jadi, melainkan suatu proses tindakan menjadi sahabat. Persahabatan itu suatu tindakan "penyeberangan" diri sendiri kepada sesamanya yang lain secara terus-menerus (transendensi). ${ }^{26}$

Jadi, dalam mangan ora mangan sing penting kumpul, orang memaknai dirinya sebagai sahabat bagi yang lain. Sahabat yang hadir sebagai Aku apa adanya. Sahabat yang mau bergerak (menyeberang) untuk mencintai. Sahabat yang mau membuka diri (diseberangi) untuk dicintai. Dengan kata lain, mangan ora mangan sing penting kumpul adalah suatu relasi persahabatan, suatu relasi cinta yang transenden, yang bergerak ke dalam (membuka diri) sekaligus ke luar bagi sesamanya. Mangan ora mangan sing penting kumpul adalah suatu relasi cinta yang saling mengisi.

Pada pembahasan di atas penulis memberi ilustrasi mengenai jembatan Suramadu sebagai sarana penyeberangan. Dalam mangan ora mangan sing penting kumpul, makanan adalah sarana penyeberangan tersebut. Makanan dalam konteks mangan ora mangan sing penting kumpul hanyalah sarana bagi masyarakat Jawa untuk meraih sesuatu yang lebih bernilai, yakni kebersamaan, persahabatan, dan relasi cinta. Makanan adalah jembatan yang efektif dan memudahkan masyarakat

\footnotetext{
${ }^{26}$ Bdk. Armada Riyanto, Berfilsafat Politik, Op. Cit., 197.
} 
Jawa untuk mengakses sesamanya. Dengan demikian, ada atau tidaknya makanan tidak menghilangkan nilai kebersamaan yang ingin dicapai dalam filosofi mangan ora mangan sing penting kumpul. Filosofi ini seolah-olah ingin berkata, "ada makanan baik, tidak ada makanan ya tidak apa-apa, yang penting kumpul".

\section{Daftar Pustaka}

Aquila, Richard E, 1992."On Plotinus and the "Togetherness" of Consciousness" Journal of the History of Philosophy, 30, (1).

Bazzano, Manu, 2014. "Togetherness: intersubjectivity revisited" Jurnal Person-Centered \& Experiential Psychotherapies. 13, (3).

Bernstein, Richard J, 1981. "Human Beings: Plurality and Togetherness" Jurnal The Review of Metaphysics. 35. (2).

Herusatoto, Budiono, 1987. Simbolisme dalam Budaya Jawa, Yogyakarta: PT. Hanindita Graha Widya.

Ihsan, Fatimah, 2018. "Solidaritas Sosial Masyarakat Jawa Perantau di Kampung Jawa Kota Tanjungpinang" Jurnal Solidaritas Sosial Masyarakat Jawa Perantau di Kampung Jawa Kota Tanjungpinang.

Irawan, Yusak, 2014. "Subjective Well Being in Javanese Collectivistic Culture". Proceeding International Conference of Revisited Asian Society. Christina Siwi dan Monica Eviandaru (eds.).
James, William, 1977. A Pluralistic Universe. Cambridge: Harvard University Press.

Maknun, T., Hasjim, M., Muslimat, M., and Hasyim, M. 2019. The form of the traditional bamboo house in the Makassar culture: A cultural semiotic study. Semiotica. In press. https://doi.org/10.1515/sem-2017-0 162

Modood, Tariq, 2001. "Their liberalism and our multiculturalism?" British Journal of Politics and International Relations. 3, (2).

$\mathrm{Ng}$, Nawi, et. Al., 2012. "Is self-rated health an independent index for mortality among older people in Indonesia?" Jurnal PloS one. 7, (4).

Riyanto, Armada, et. Al. (eds.) 2011. Aku dan Liyan: Kata Filsafat dan Sayap, Malang: Widya Sasana Publication.

Riyanto, Armada, et. Al. (eds). 2011. Berfilsafat Politik. Yogyakarta: Kanisius.

Riyanto, Armada, et. Al. (eds.). 2018. Relasionalitas. Yogyakarta: Kanisius.

Roqib, Moh. 2007. Harmoni dalam Budaya Jawa. Purwokerto: STAIN Purwokerto Press.

\section{Sumber Internet}

Https://kbbi.kemdikbud.go.id/entri/penyeb erangan (diakses pada 1 November 2018).

Https://kbbi.kemdikbud.go.id/entri/selamat an (diakses pada 19 Oktober 2018). 